Jpn. J. Phys. Fitness Sports Med., 60 (3) : 295 304 (2011)

\title{
EFFECTS OF ACUTE PROLONGED STRENUOUS EXERCISE ON THE SALIVARY STRESS MARKERS AND INFLAMMATORY CYTOKINES
}

\author{
TATSUYA USUI ${ }^{1)}$, TAKAHIRO YOSHIKAWA ${ }^{1)}$, SHIN-Ya UEdA ${ }^{2)}$, \\ YOSHIHIRO KATSURA ${ }^{3)}$, KEISUKE ORITA ${ }^{1)}$ and SHIGEO FUJIMOTO ${ }^{1)}$
}

(Received March 4, 2011; Accepted April 2, 2011)

\begin{abstract}
The aim of the present study was to examine whether amount of oral cortisol, immunoglobulin A ( $\operatorname{IgA}$ ), chromogranin A ( $\mathrm{Cg} A)$ and inflammatory cytokines, might be affected by prolonged strenuous exercise. Ten young male volunteers either exercised on recumbent ergometer at $75 \% \dot{\mathrm{V}}_{2}$ max for 60 min (exercise session) or sat quietly (resting session). Saliva samples were obtained at $60 \mathrm{~min}$ intervals during sessions for measurements of salivary stress markers (cortisol, IgA and $\mathrm{CgA}$ ), salivary inflammatory cytokines, such as interleukin-1 $\beta$ (IL-1 $\beta$ ), interleukin-6 (IL-6) and tumor necrosis factor- $\alpha(\mathrm{TNF}-\alpha)$ and osmolality. Saliva flow rate was decreased and saliva osmolality was increased during the 60-min exercise. Saliva cortisol and CgA concentrations and secretion rates were increased during and after the exercise, whereas saliva IgA concentration and secretion rates were decreased after the exercise. Salivary inflammatory cytokines was increased during and after the exercise. The present findings suggested a single bout of prolonged strenuous exercise caused a transient increase in the salivary cortisol, CgA and inflammatory cytokines levels, whereas salivary IgA concentration and secretion rates were decreased after the exercise. Further studies, however, are needed to delineate whether or not salivary stress markers and inflammatory cytokines may be used as biological markers to determine the host responses to acute prolonged strenuous exercise.
\end{abstract}

(Jpn. J. Phys. Fitness Sports Med., 60 (3) : 295 304 (2011))

Key words : Physical stress, Saliva stress markers, inflammatory cytokines

\section{I . INTRODUCTION}

Strenuous exercise activates the hypothalamicpituitary-adrenal (HPA) axis and the sympathoadrenal medullary system $(\mathrm{SAM})^{1,2)}$. Acute stress has been reported to increase the activity of the HPA axis with subsequent rise in salivary cortisol level ${ }^{3,4)}$. Salivary immunoglobulin A (IgA) and chromogranin A ( $\mathrm{CgA}$ ) may be a sensitive and quantitative index of the activity of the SAM system $^{5,6)}$. These salivary biomarkers have made it possible to scientifically investigate the effect of stresses ${ }^{5,6)}$. Saliva has been the increasingly investigated as an easily accessible fluid that may indicate systemic alterations due to exercise ${ }^{7)}$. The stress hormones play an important role in meeting the circulatory and nutritional demands of a potentially dangerous situation through a "fight or flight" response ${ }^{8)}$. Cortisol is secreted from the adrenal gland into the serum and saliva under

\footnotetext{
1) 大阪市立大学大学院医学研究科運動生体医学 干545-8585 大阪府大阪市阿倍野区旭町1-4-3

2) 国立循環器病研究センター研究所 干565-8565 大阪府吹田市藤白台5-7-1

3) 工学院大学共通課程保健体育科 干192-0015 東京都八王子市中野町2665-1
}

Department of Sports Medicine, Osaka City University Graduate School of Medicine, Osaka, Japan 1-4-3, Asahi-machi, Abeno-ku, Osaka, 545-8585, JAPAN National Cerebral and Cardiovascular Center Research Institute 5-7-1 Fujishirodai, Suita, Osaka, 565-8565, JAPAN Kogakuin University, Common Course, Department of Health and Physical Education 2665-1, Nakano-cyo, Hachioji-city, Tokyo, 192-0015, JAPAN 
physical and psychological stress, and that the tendencies of secretion in both serum and saliva are nearly consistent with each other ${ }^{6,9,10)}$. Circulating cortisol is also dependent on the intensity of exercise, with elevations occurring following intensities above approximately 60\% of maximal oxygen uptake $\left(\dot{\mathrm{V}} \mathrm{O}_{2} \max \right)^{11)}$. IgA is the most prevalent in mucosal secretions and it serves as the first line of defense against viral infection ${ }^{12)}$. Current evidence suggests that exercise brings about a change depends on the intensity, duration, and chronicity of exercise ${ }^{13)}$. Previous studies explored the relationship between salivary IgA and chronic exposure to physical stress or in individuals particularly prone to stress. Such studies consistently revealed stress-related downregulation ${ }^{14)}$. CgA exists in various endocrine organs and its secretion is regulated by the SAM system ${ }^{15,16)}$. In vitro experiments have also demonstrated that CgA exhibits antifungal and antibacterial properties ${ }^{17,18)}$. Salivary $\mathrm{CgA}$ concentration increases rapidly under psychosomatic stress ${ }^{19)}$, although the response of $\mathrm{CgA}$ to exercise is yet to be determined. Exercise is a prototype of physical stressor that induces a host of hormonal, metabolic, cardiovascular and immunological change. The bodily response to muscle damage is similar to the acute-phase response to inflammation resulting from infection ${ }^{20,21)}$. Inflammatory cytokines, such as interleukin-1 $\beta$ (IL-1 $\beta$ ), interleukin-6 (IL-6) and tumor necrosis factor- $\alpha(\mathrm{TNF}-\alpha)$ participate in this response in a cascade-like fashion ${ }^{21}$. These cytokine are a family of low-molecular weight, cell-to-cell mediators that regulate many immune and inflammatory responses ${ }^{22)}$. Previous studies of very strenuous exercise in adult subjects have demonstrated robust increases in the circulating levels of $\mathrm{IL}^{-1} \beta$, $\mathrm{TNF}-\alpha$ and $\mathrm{IL}-6^{22 \sim 24)}$. However, reports showing the levels of this inflammatory cytokines in saliva before, during and after acute exercise are lacking. To our knowledge, only one study confirms the saliva stress markers and inflammatory cytokine using the same sample of subjects in acute exercise ${ }^{4)}$.
The purpose of present study was to investigate changes in levels of saliva cortisol, IgA, CgA and inflammatory cytokines response to a single bout of prolonged strenuous exercise.

\section{METHODS}

\section{A. Subjects}

Ten young male university students (mean \pm SD: age $23 \pm 3 \mathrm{yr}$; height $176.4 \pm 3.4 \mathrm{~cm}$; body mass $66.8 \pm 7.8 \mathrm{~kg} ; \dot{\mathrm{V} O}{ }_{2} \max 49.7 \pm 4.8 \mathrm{ml} / \mathrm{kg}$ / min) volunteered to participate in the present study. All subjects reported as 1) being active in recreational sport and physical activity courses, but having never participated in any training for any particular sports, 2) being life-long non-smokers ${ }^{25)}$, 3) not having a history of respiratory and allergic diseases, including asthma, rhinitis and eczema ${ }^{26)}$, 4) not having psychological diseases nor having experienced any significant life events, such as death, accident or divorce in family within the previous 6 months ${ }^{27)}$. Subjects who had a respiratory infection, a dental problem or any medications within 4 weeks prior to the study were excluded because these conditions might affect the baseline secretion of the immunological peptides in oral cavity ${ }^{28)}$. All subjects provided written informed consent for participation in the study, which was approved by the Ethics Committee of Osaka City University.

\section{B. Experimental design}

Prior to the two experimental sessions, subjects performed ramp exercise test $(20 \mathrm{~W} / \mathrm{min})$ by a recumbent ergometer (Strengthergo, Mitsubishi, Tokyo, Japan) to determine $\dot{\mathrm{V}} \mathrm{O}_{2}$ max after 3-min rest on the ergometer and a 3-min $0 \mathrm{~W}$ warm-up as we previously described ${ }^{29)}$. $\dot{\mathrm{V}} \mathrm{O}_{2}$ max was measured with an AE-280S Aeromonitor (Minato Medical Science Inc., Tokyo, Japan). Ventilatory and $\mathrm{O}_{2}$ consumption variables were calculated using the breath-by-breath method.

Subjects took part in two experimental sessions (exercise and resting conditions) at least 7 days apart. The order of the two session days was ran- 
domized across subjects. The design of the experimental session is shown diagrammatically in Figure 1. The present studies were performed during the afternoon according to a previous study ${ }^{5)}$. For 24 hrs before each session, subjects were requested to abstain from drinking caffeine because caffeine ingestion was reported to affect secretion of cortisol and IgA in saliva during strenuous exercise ${ }^{30)}$, as well as to refrain from intake of alcohol according to a previous study ${ }^{5)}$. Subjects arrived at our laboratory more than 30-min before the start time of exercise testing without having lunch and were asked to sit quietly in order to avoid any physical stress before the tests. About 10-min before the exercise, a saliva sample was collected $(t=0)$. And then, subjects were asked to wear a mask for measurement of $\dot{\mathrm{V}}_{2}$ immediately before the beginning of exercise. At 13:00 p.m. ( $t=0 \mathrm{~min})$, the subject either exercised on the recumbent ergometer at $75 \% \dot{\mathrm{V}}_{2}$ max for 60 min (exercise session) or sat while allowed to read or write quietly (resting session). To ensure that the subject remained at the prescribed workload, $\dot{\mathrm{V}}_{2}$ was continuously monitored during exercise using the breath-by-breath method. Immediately after the end of exercise, subjects took off the mask, followed by saliva collection $(t=60 \mathrm{~min})$. Saliva samples were obtained at 60 min intervals after exercise $(t=120,180 \mathrm{~min})$. On the day of resting session, saliva samples were collected at the same time points of exercise session $(t=0,60,120,180 \mathrm{~min})$. To negate the effect of wearing mask for measurement of $\dot{\mathrm{V}}_{2}$ during exercise on saliva flow, subjects were asked to wear the mask during the resting session as well. All subjects were asked to refrain from consuming any fluids during the entire period of $3 \mathrm{hr}$ observation.

\section{Saliva collection}

We selected the cotton swab method of saliva collection ${ }^{31)}$ in order to obtain sufficient volume of samples for assessment of a wide variety of saliva components from untrained volunteers (nonathletes) who were instructed to perform the unaccustomed strenuous exercise without producing additional unpleasant stress by compulsory spitting instruction. Briefly, subjects sat and rinsed out their mouths with sterilized water $(30-\sec \times$ 3 times). Saliva induction was stimulated by chewing of sterilized cotton swab for one minute at a frequency of 1 chew sec ${ }^{-1}$. Then, each subject was asked to pull the cotton out of his mouth followed by extraction of saliva sample from the cotton. The whole saliva volume (mL) was estimated by weighing to the nearest milligram and the saliva density was assumed to be $1.0 \mathrm{~g} \mathrm{~mL}^{-1}$. The saliva flow rate $\left(\mathrm{mL} \mathrm{min}^{-1}\right)$ was represented as the

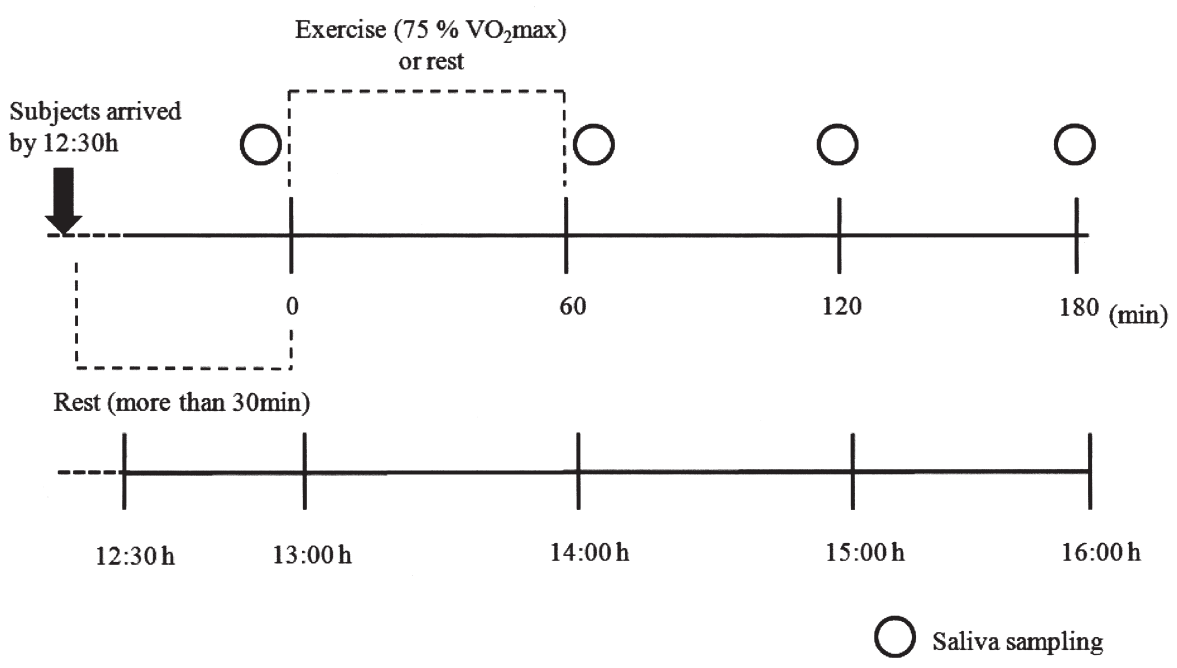

Figure 1 Scheme of the present study 
whole saliva volume. The saliva supernatant was stored at $-80{ }^{\circ} \mathrm{C}$ for subsequent assays.

\section{Salivary stress marker analysis}

An enzyme-linked immunosorbent assay (ELISA) was used for measurements of the saliva concentrations of cortisol (Parameter Cortisol Assay, R\&D Systems, Minneapolis, MN), IgA (EIA-sIgA Test, Medical and Biological Laboratories Co., Ltd., Nagoya, Japan), CgA (YK070:Yanaihara Institute Inc., Shizuoka, Japan), respectively. The present cortisol assay measured both of free and corticosteroid-binding globulin-bound form of cortisol ${ }^{32)}$. The interassay coefficients of variation were less than 9.1, 7.4 and $10 \%$ for the cortisol, IgA and $\mathrm{CgA}$ assays, respectively. The minimum detection limit for the cortisol, $\operatorname{Ig} \mathrm{A}$ and $\operatorname{Cg} \mathrm{A}$ assays is 0.03 ng $\mathrm{mL}^{-1}, 0.06 \mu \mathrm{g} \mathrm{mL}^{-1}$ and $0.137 \mathrm{pmol} \mathrm{ml}^{-1}$ respectively. All sample measurements were performed in duplicate according to the manufacturers' instructions. Secretion rate of each parameter in saliva was calculated by multiplying saliva flow rate by saliva concentration of each component. Saliva osmolality was determined by freezing point depression using a cryoscopic osmometer (Osmomat 030, Gonotec, GbBH, Berlin, Germany) calibrated with $300 \mathrm{mOsmol} \mathrm{kg}{ }^{-1} \mathrm{NaCl}$ solution. The requisite volume of saliva samples were $50 \mu$ l of each osmolality measurement, and the average value was calculated from three measurements in each saliva sample. The interassay coefficients of variation for the osmolality assay were less than $1 \%$.

\section{E. Inflammatory cytokine analysis}

Saliva samples for measurements of IL-1 $\beta$, IL-6 and $\mathrm{TNF}-\alpha$ were analyzed by commercially available enzyme-linked immunosorbent assay (BioRad, Bio-Plex Pro Assays, CA, USA). The interassay coefficients of variation were less than 7.5, 7.8 and $7.8 \%$ for the IL-1 $\beta$, IL- 6 and TNF- $\alpha$ assays, respectively. The minimum detection limit for the $\mathrm{IL}^{-1} \beta, \mathrm{IL}-6$ and $\mathrm{TNF}-\alpha$ assays is $0.1 \mathrm{pg} \mathrm{mL}^{-1}, 1.6$ $\mathrm{pg} \mathrm{mL}^{-1}$ and $0.14 \mathrm{pg} \mathrm{ml}^{-1}$ respectively. All sample measurements were performed in duplicate according to the manufacturers' instructions.

\section{F. Statistical analysis}

All statistical analyses were performed using SPSS for Windows (SPSS Inc., Chicago, IL). All data were normally distributed, and presented as mean \pm S.D. To examine the effects of exercise on all blood and saliva parameters measured, two-way ANOVA with repeated measures was performed. If statistical significance was detected, post-hoc multiple pairwise comparisons (TukeyKramer test) were performed.

\section{RESULTS}

\section{A. Physiological Variables}

The mean values of work rate, $\dot{\mathrm{V}} \mathrm{O}_{2}, \% \dot{\mathrm{V}} \mathrm{O}_{2} \mathrm{max}$, heart rate (HR), respiratory exchange ratio (RER) during the exercise session were $142 \pm 20 \mathrm{w}$, $2262 \pm 353 \mathrm{ml} \mathrm{min}^{-1}, 75.9 \pm 1.2 \% \mathrm{~V}_{2} \max , 169 \pm 12 \mathrm{bpm}$ and $1.1 \pm 0.1$, respectively.

\section{B. Main characteristics of saliva flow and osmolality}

Time courses of salivary flow rate and osmolality are presented in Table 1. Saliva flow rate was significantly decreased during $60-$ min exercise in comparison to the resting session (main effects of time; $P<0.001$, main effect of session; $P<0.001$, and time $\times$ session interaction effect; $P<0.001$ ). A transient increase in saliva osmolality was observed during the 60-min exercise (main effects of time; $P<0.001$, main effect of session; $P<0.001$, and time $\times$ session interaction effect; $P<0.001)$.

\section{Effect of acute strenuous exercise on salivary stress markers}

Figure 2A-2C shows changes over time in amount of salivary stress markers expressed by two variables; direct concentration, secretion ratio. And secretion rate of each component are presented in the Table 2 . None of the baseline values $(t=0)$ of these measured variables differed sig- 
Table 1. Time course of saliva flow rate during resting and exercise sessions.

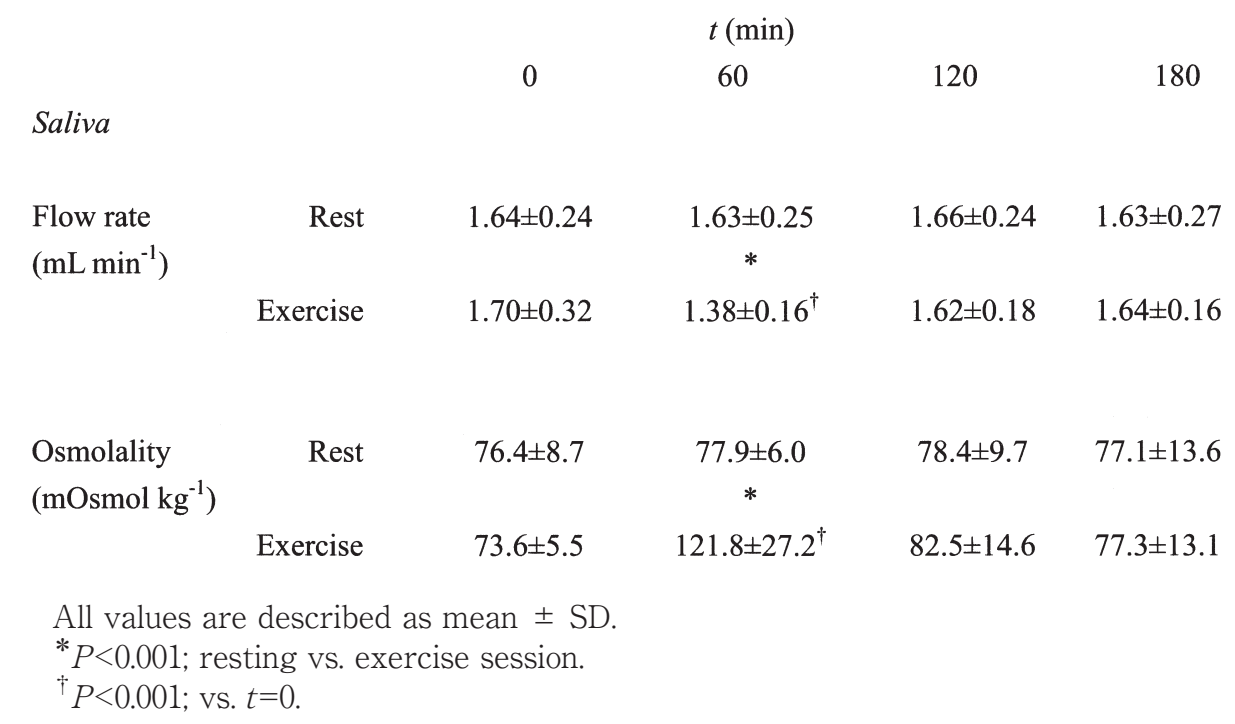

nificantly between sessions. Following the 60-min exercise $(t=60$ to $t=180)$, significant rises in saliva cortisol and $\mathrm{CgA}$ concentration and secretion ratio were observed (main effect of time; $P<0.001$, main effect of session; $P<0.001$, and time $\times$ session interaction effect; $P<0.001$, respectively). In contrast, saliva IgA levels did not differ from those in the resting session during exercise but decreased for 2 hrs following the exercise, as shown by main effects of time (concentration; $P=0.007$, secretion ratio; $P=0.022$ ), those of session (concentration; $P=0.015$, secretion ratio; $P=0.026)$, and by time $\times$ session interaction effect (concentration; $P=0.003$, secretion ratio; $P=0.011$ ).

\section{Effect of acute exercise on inflammatory cytokines}

Figure $3 \mathrm{~A}-3 \mathrm{C}$ shows changes over time in amount of salivary inflammatory cytokine levels expressed by two variables; direct concentration, secretion ratio. And secretion rate of each component are presented in the Table 2 . A significant increases in the salivary IL-1 $\beta$ levels were observed during the exercise session compared with those during the resting session, as indicated by main effects of time (concentration; $P<0.001$, secretion ratio; $P<0.001$ ) and those of session (concen- tration; $P<0.001$, secretion ratio; $P<0.001$ ) and the time $\times$ session interaction effect (concentration; $P<0.001$, secretion ratio; $P<0.001$ ). The levels of salivary IL-6 were significantly increased during the exercise session compared with those during the resting session, as indicated by main effects of time (concentration; $P<0.001$, secretion ratio; $P<0.001$ ) and those of session (concentration; $P<0.001$, secretion ratio; $P<0.001)$ and the time $\times$ session interaction effect (concentration; $P<0.001$, secretion ratio; $P<0.001$ ). In parallel with the $\mathrm{IL}-1 \beta$ and IL-6, significant increases in the salivary $\mathrm{TNF}-\alpha$ levels were observed during the exercise session compared with those during the resting session, as indicated by main effects of time (concentration; $P<0.001$, secretion ratio; $P<0.001$ ) and those of session (concentration; $P<0.001$, secretion ratio; $P<0.001)$ and the time $\times$ session interaction effect (concentration; $P<0.001$, secretion ratio; $P<0.001$ ).

\section{N. DISCUSSION}

The main objectives of the present study were to assess the effect of a single bout of prolonged strenuous exercise on salivary stress markers and inflammatory cytokines in young adult subjects. The present study has revealed the following evidence: 1) A single bout of prolonged strenu- 

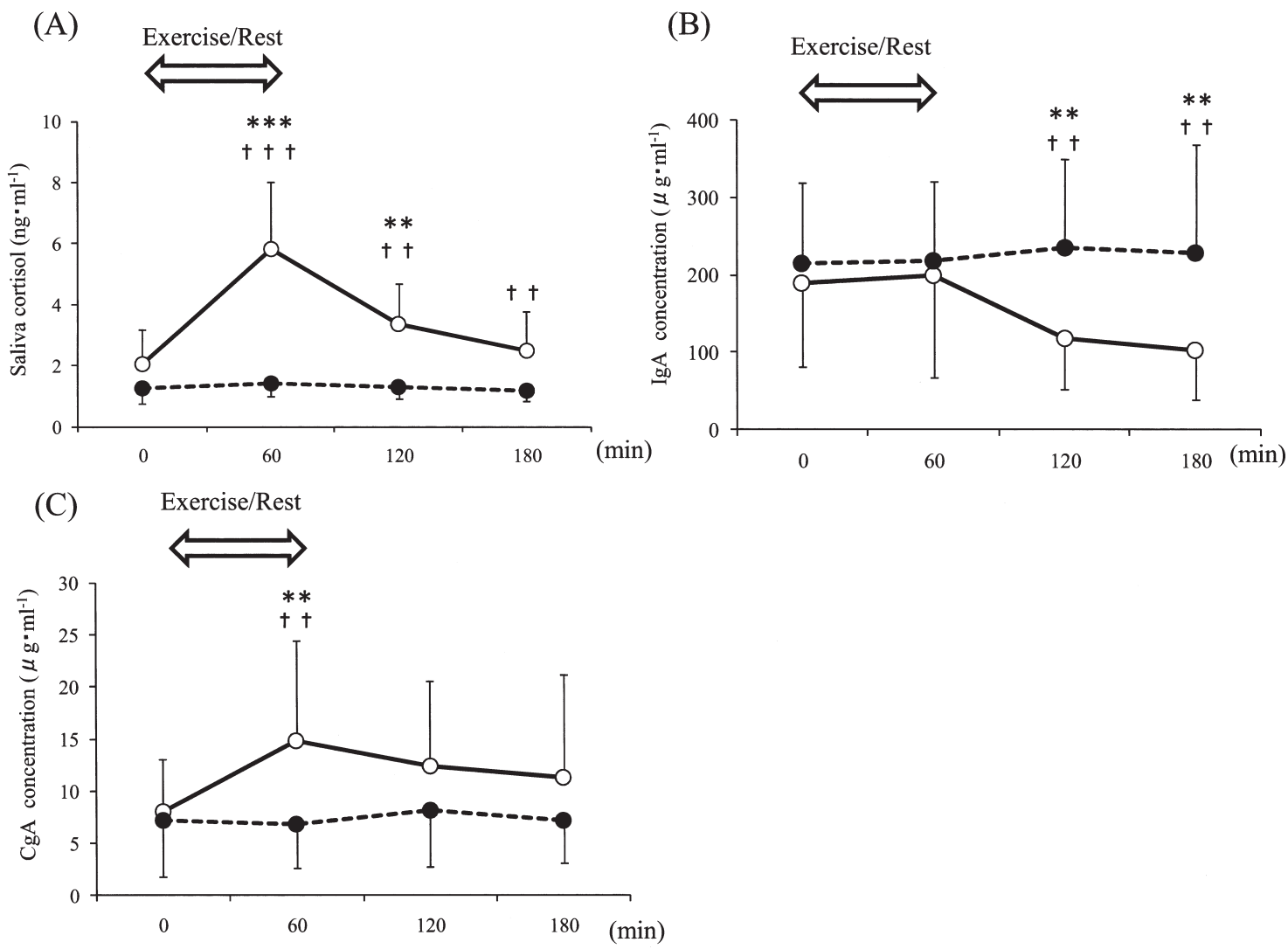

Figure 2 Time course of changes in saliva levels of cortisol concentration(A), IgA concentration (B), CgA concentration $(\mathrm{C})$ during exercise $(O)$ and resting $(\bullet)$ sessions. Mean values \pm S.D. are presented. Two-way ANOVA for repeated Measures: (A) main effects of time: $P=0.001$, main effects of session: $P=0.001$. (B) main effects of time: $P=0.007$, main effects of session: $P=0.01$. (C) main effects of time: $P=0.001$, main effects of session: $P=0.001{ }^{*} * P<0.01{ }^{*} * * P<0.001$ : resting versus exercise session. ${ }^{\dagger \dagger} P<0.01,{ }^{\dagger \dagger \dagger} P<0.001$ : versus 0 time.

ous exercise $\left(75 \% \dot{\mathrm{V}}_{2} \max\right.$ for $\left.60 \mathrm{~min}\right)$ caused a transient increase in the salivary stress markers compared with those in the resting session. 2) In parallel with these changes, significant increases were observed in salivary inflammatory cytokines. It is well known that physical and mental stress elicit the release of cortisol from HPA axis, by which stress can modulate various immune responses ${ }^{33)}$. Exercise in the present study could cause comparable increases in saliva cortisol levels to those observed in previous studies ${ }^{34,35)}$. Cortisol is important hormone in the regulation of intermediate metabolism and stress. It exists in free and protein-bound forms in serum, but only in a free from in saliva due to the lack of secreted binding proteins ${ }^{36)}$. It is advantageous to collect multiple samples with time intervals of $1-4 \mathrm{~h}$ in order to follow the diurnal variation and estimate the total secretion of cortisol in saliva during the time interval. This procedure also minimizes the risk of incorrect decisions based on false cortisol results. For instance, physical activity $>60 \%$ of $\dot{\mathrm{V}}_{2} \max$ for $>20$ min gives a significant increase in cortisol for about $2 \mathrm{~h}^{36,37)}$. The present findings highlight the variability of stress-induced immunological shifts in response to strenuous exercise among innate immune factors. To investigate an impact of stress on innate immunity and subsequent susceptibility or resistance to oral or airway pathogens, it is likely informative to elucidate whether and how 
Table 2. Time course of saliva secretion rate of salivary stress markers and inflammatory cytokines during resting and exercise sessions.

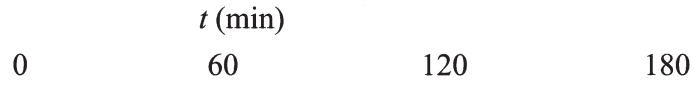

Salivary stress markers

Saliva cortisol $\left(\mathrm{pg} \mathrm{min}{ }^{-1}\right)$

$\begin{array}{rcccc}\text { Rest } & 2.0 \pm 0.9 & 2.2 \pm 0.9 & 2.1 \pm 0.8 & 1.9 \pm 0.8 \\ & & * * * & * * * & * * \\ \text { Exercise } & 3.7 \pm 2.4 & 9.5 \pm 4.0^{\dagger \dagger \dagger} & 5.7 \pm 2.4^{\dagger \dagger} & 3.9 \pm 2.2\end{array}$

Saliva IgA $\left(\mu \mathrm{g} \mathrm{min}^{-1}\right)$

$\begin{array}{rcccc}\text { Rest } & 306.6 \pm 119.0 & 310.0 \pm 113.2 & \begin{array}{c}339.1 \pm 134.6 \\ *\end{array} & 309.5 \pm 163.4 \\ & & & * \\ \text { Exercise } & 284.4 \pm 120.8 & 296.6 \pm 219.2 & 182.0 \pm 93.6^{\dagger} & 161.2 \pm 93.4^{\dagger}\end{array}$

Saliva $\operatorname{Cg} A\left(\mu \mathrm{g} \min ^{-1}\right)$

$\begin{array}{ccccc}\text { Rest } & 11.5 \pm 7.6 & 10.3 \pm 6.1 & 11.8 \pm 9.0 & 10.6 \pm 5.6 \\ & & * * * & * * * & * * \\ \text { Exercise } & 11.8 \pm 5.2 & 19.8 \pm 11.4^{\dagger \dagger \dagger} & 19.2 \pm 11.2^{\dagger \dagger \dagger} & 17.1 \pm 13.9^{\dagger \dagger}\end{array}$

Inflammatory cytokines

$I L-1 \beta\left(\mathrm{pg} \mathrm{min}{ }^{-1}\right)$

$\begin{array}{rcccc}\text { Rest } & 0.6 \pm 0.1 & 0.6 \pm 0.1 & 0.6 \pm 0.2 & 0.7 \pm 0.1 \\ & & * * & * \\ \text { Exercise } & 0.7 \pm 0.1 & 2.3 \pm 0.2^{\dagger \dagger} & 1.2 \pm 0.2^{\dagger} & 0.9 \pm 0.2\end{array}$

$I L-6\left(\mathrm{pg} \mathrm{min}{ }^{-1}\right)$

$\begin{array}{rcccc}\text { Rest } & 4.1 \pm 1.4 & \begin{array}{c}4.1 \pm 1.3 \\ * *\end{array} & 4.6 \pm 1.2 & 4.3 \pm 1.1 \\ & & & \\ \text { Exercise } & 4.9 \pm 1.4 & 9.5 \pm 3.5^{\dagger \dagger} & 5.7 \pm 2.4^{\dagger} & 5.8 \pm 2.2\end{array}$

$T N F-\alpha\left(\mathrm{pg} \mathrm{min}^{-1}\right)$

$\begin{array}{rcccc}\text { Rest } & 5.1 \pm 1.3 & 4.6 \pm 0.9 & 4.8 \pm 0.8 & 4.5 \pm 1.2 \\ & & * * & * & \\ \text { Exercise } & 5.5 \pm 1.4 & 12.5 \pm 4.4^{\dagger \dagger} & 7.6 \pm 3.4^{\dagger} & 6.4 \pm 3.1\end{array}$

All values are described as mean $\pm \mathrm{SD}$.

${ }^{*} P<0.05,{ }^{*} P<0.01,{ }^{* * *} P<0.001$; resting vs. exercise session.

${ }^{\dagger} P<0.05,{ }^{\dagger} P<0.01,{ }^{\dagger \dagger \dagger} P<0.001$; vs. $t=0$.

the stress can or cannot be involved in kinetics of individual local immune components. In this study, salivary IgA levels were decreased for 2 hrs following the exercise. Mackinnon suggests that IgA concentration relative to total saliva proteins is the best indication of the effects of acute exercise on mucosal immunoglobulin levels because it adjusts for exercise induced change in saliva volume ${ }^{38)}$.
Salivary IgA has been classically recognized as one of major effectors in host resistance to many pathogens in oral cavity, and many studies investigated the impact of transient or repeated exercise on its salivary levels ${ }^{39,40)}$. Decreases in salivary IgA have been observed after different types of intense prolonged exercise, such as $20-50 \mathrm{~km}$ crosscountry skiing, $2-\mathrm{h}$ cycling at $70-75 \% \dot{\mathrm{V}} \mathrm{O}_{2} \max , 2-\mathrm{h}$ 

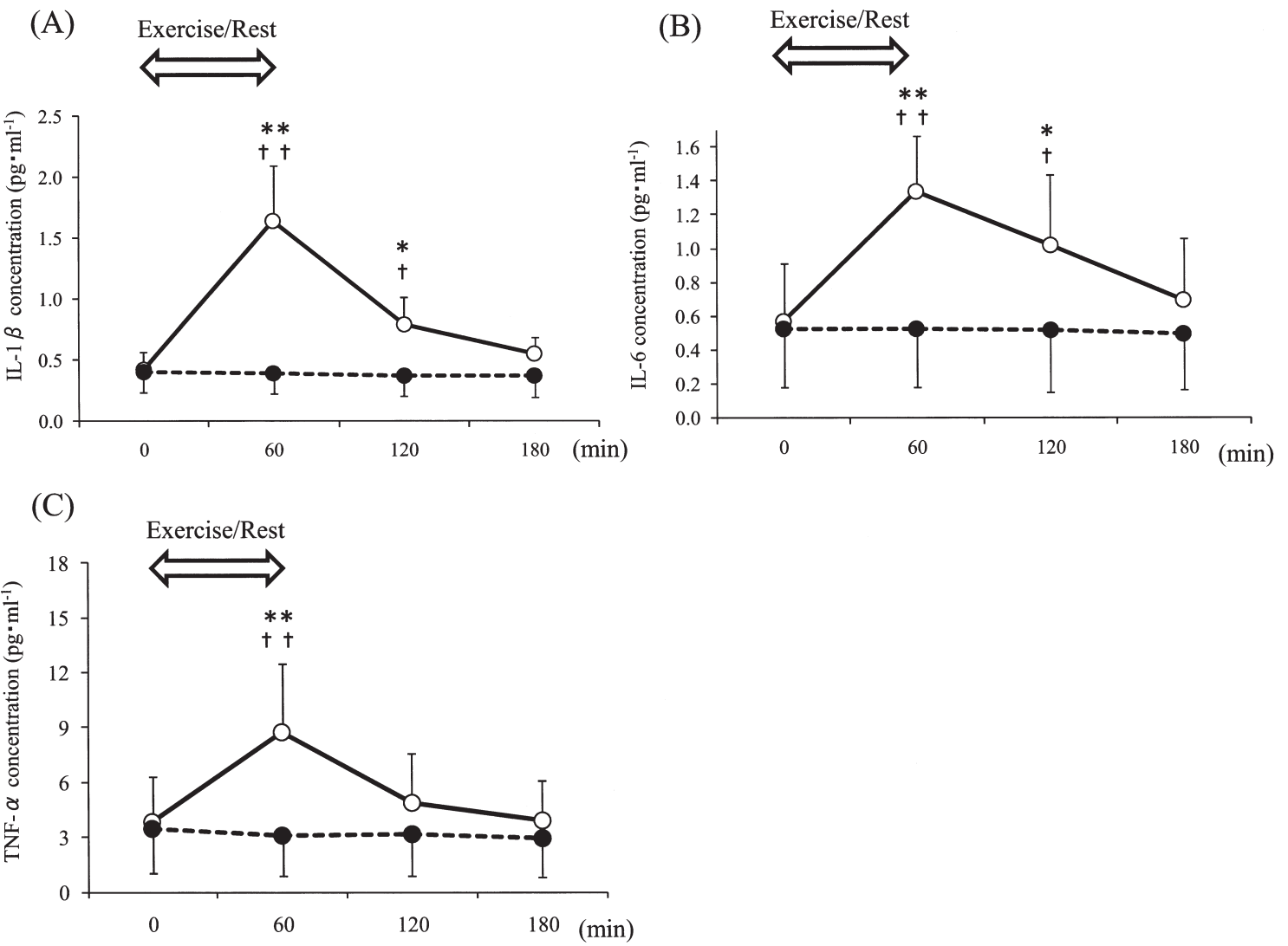

Figure 3 Time course of changes in saliva levels of IL-1 $\beta$ concentration(A), IL-6 concentration $(\mathrm{B}), \mathrm{TNF}-\alpha$ concentration $(\mathrm{C})$ during exercise $(\mathrm{O})$ and resting $(\bullet)$ sessions. Mean values \pm S.D. are presented. Two-way ANOVA for repeated Measures: (A) main effects of time: $P=0.01$, main effects of session: $P=0.01$. (B) main effects of time: $P=0.01$, main effects of session: $P=0.01$. (C) main effects of time: $P=0.01$, main effects of session: $P=0.01 .{ }^{*} P<0.05$, ${ }^{*} P<0.01$ : resting versus exercise session. ${ }^{\dagger} P<0.05,{ }^{\dagger} P<0.01$ : versus 0 time.

swim training, and marathon running ${ }^{41)}$. Accordingly, it is possible that some types of exercise might modify the state of immune readiness of oral mucosa and cavity. In the present study, we measured $\mathrm{CgA}$ to reflect changes in sympathetic activity. A significant increase in both the concentration and secretion rate of $\mathrm{CgA}$ was observed after exercise and both were influenced by the prolonged strenuous exercise. These findings lend further support to an increased involvement of sympathetic activity in the prolonged strenuous exercise sessions. Results of the present study show that elevated levels of inflammatory cytokines can also be detected in saliva after acute prolonged strenuous exercise. The present study results are simi- lar to the alteration responses in serum levels of inflammatory cytokines after acute exercise ${ }^{4,23)}$. However, the precise mechanism by which the levels of salivary inflammatory cytokines were increased after acute prolonged strenuous exercise. Cytokines are group of low molecular weight regulatory proteins secreted by white blood cells and a variety of other body cells in response to a number of inducing stimuli. Exercise in the heat, however, did not augment the exercise induced suppression of stimulated cytokine production, despite there being elevated levels of stress hormones ${ }^{42)}$. Strenuous exercise induces increased the levels of inflammatory cytokines. Thus, increased plasma levels of IL-1 $\beta$, IL- 6 , TNF- $\alpha$ are found after strenuous 
exercise. The concentration of IL-6 increases up to 100-fold after a marathon race ${ }^{43)}$.

Our work has several limitations. First, we did not completely discriminate the impact of purely physical stress from that of psychological one on hormonal and immune peptides. In the setting of the present study, all subjects experienced ergometer exercise and were familiar with the test procedures in advance of two experimental sessions when they visited for the measurements of $\dot{\mathrm{V}} \mathrm{O}_{2}$ max, thus anticipatory responses were less likely. However, it will be necessary to examine additionally the impact of psychological stress by assessing other psychological parameters. Secondly, we recruited a small number of subjects in the present study. The positive findings in the small sample size need to be repeated by other independent studies because of the tendency for false positive results.

\section{Conclusions}

The present findings suggested a single bout of prolonged strenuous exercise caused a transient increase in the salivary cortisol, $\mathrm{CgA}$ and inflammatory cytokines levels, whereas salivary IgA concentration and secretion rates were decreased after the exercise. Further studies, however, are needed to delineate whether or not salivary stress markers and inflammatory cytokines may be used as biological markers to determine the host responses to acute prolonged strenuous exercise. It is possible that, while prolonged strenuous exercise could partly enhance the oral innate immunity, the physical stress could simultaneously restrict the immunological enhancement by the activity of HPA axis.

\section{REFERENCES}

1) Leal-Cerro A, Gippini A, Amaya MJ, Lage M, Mato JA, Dieguez C, Casanueva FF. Mechanisms underlying the neuroendocrine response to physical exercise. J Endocrinol Invest. 26: 879-885, 2003.

2) Luger A, Deuster PA, Kyle SB, Gallucci WT, Montgomery LC, Gold PW, Loriaux DL, Chrousos GP. Acute hypothalamic-pituitary-adrenal responses to the stress of treadmill exercise. Physiologic adaptations to physical training. $N$ Engl J Med. 316: 130915, 1987.

3) Kirschbaum C, Hellhammer DH. Salivary cortisol in psychoneuroendocrine research: recent developments and applications. Psychoneuroendocrinology. 19: 313-33, 1994.

4) Rahman ZA, Adbullah N, Singh R, Sosroseno W. Effect of acute exercise on the levels of salivary cortisol, tumor necrosis factor- $\alpha$ and nitric oxide. Journal of Oral Science. 52: 133-136, 2010.

5) Allgrove JE, Gomes E, Hough J, Gleeson M. Effects of exercise intensity on salivary antimicrobial proteins and markers of stress in active men. $J$ Sports Sci. 26: 653-61, 2008.

6) Lippi G, Vita FD, Salvagno GL, Gelati M, Montagnana M, Guidi GC. Measurement of morning saliva cortisol in athletes. Clinical Biochemistry. 42: 904906, 2009.

7) Chicharro JL, Lucía A, Pérez M, Vaquero AF, Ureña R. Saliva composition and exercise. Sports Med. 26: 17-27, 1998.

8) McEwen BS. Protective and damaging effects of stress mediators: central role of the brain. Dialogues in Clinical Neuroscience. 8: 368-381, 2006.

9) Dorn LD, Lucke JF, Loucks TL, Berga SL. Salivary cortisol reflects serum cortisol: analysis of circadian profils. Ann Clin Biochem. 44: 281-284, 2007.

10) Törnhage CJ. Salivary cortisol for assessment of hypothalamic-pituitary-adrenal axis function. Neuroimmunomodulation. 16: 284-9, 2009.

11) Viru A, Viru M. Cortisol - an essential adaptation hormone in exercise. International Journal of Sports Medicine. 25: 461-464, 2004.

12) MacKinnon LT. Chronic exercise training effects on immune function. Med Sci Sports Exerc. 32: S369S376, 2000.

13) Blannin AK, Robson PJ, Walsh NP, Clark AM, Glennan L, Gleeson M. The effect of exercising to exhaustion at different intensites on saliva immunoglobulin A, protein and electrolyte secretion. Int J Sports Med. 19: 547-552, 1998.

14) Hucklebridge F, Clow A, Evans P. The relationship between salivary secretory immunoglobulin $\mathrm{A}$ and cortisol: neuroendocrine response to awakening and the diurnal cycle. International Journal of Psychophysiology. 31: 69-76, 1998.

15) Helle KB. Some chemical and physical properties of the soluble protein fraction of bovine adrenal chromaffin granules. Mol Pharmacol. 2: 298-310,1966.

16) Winkler H, Fiscer $C R$. The chromogranin $A$ and $B$ : The first 25 years and future perspectives. Neuroscience. 49: 497-528, 1992.

17) Lugardon K, Raffner R, Goumon Y, Corti A, Delmas 
A, Bulet P. Antibacterial and antifungal activities of vasostatin-1, the N-terminal fragment of chromogranin A. Journal of Biological Chemistry. 275: 10745-10753, 2000.

18) Strub JM, Gouman Y, Lugardon K, Capon C, Lopez M, Moniatte M. Antibactcrial activity of glycosylated and phosphorylated chromogranin A-derived peptide from bovine adrenal medullary chromaffin granules. Journal of Biological Chemistry. 271: 173194, 1996.

19) Nakane H, Asami O, Yamada $Y$, Harada T, Matsui N, Kanno T. Salivary chromogranin A as an index of psychosomatic stress response. Biomedical Research. 19: 401-406, 1998.

20) Gudmundsson A, Ershler WB, Goodman B, Lent SJ, Barczi S, Carnes M. Serum concentrations of interleukin -6 are increased when sampled through an indwelling venous catheter. Clin Chem. 43: 2199-2201, 1997.

21) Turnbull AV, Rivier CL. Regulation of the hypothalamic-pituitary-adrenal axis by cytokines: actions and mechanisms of action. Physiol Rev. 79: 1-71, 1999.

22) Pedersen BK, Toft AD. Effects of exercise on lymphocytes and cytokines. Br J Sports Med. 34: 246251, 2000.

23) Ostrowaki K, Rohde T, Asp S, Schjerling P, Pedersen BK. Pro- and anti-inflammatory cytokine balance in strenuous exercise in humans. Journal of Physiology. 515: 287-291, 1999.

24) Pedersen BK. Exercise and Cytokines. Immunology and Cell Biology. 78: 532-535, 2000.

25) Herr C, Beisswenger C, Hess C, Kandler K, Suttorp N, Welte T, Schroeder JM, Vogelmeier C; R Bals for the CAPNETZ Study Group. Suppression of pulmonary innate host defence in smokers. Thorax. 64: 144-9, 2009.

26) Beisswenger C, Kandler K, Hess C, Garn H, Felgentreff K, Wegmann M, Renz H, Vogelmeier C, Bals R. Allergic airway inflammation inhibits pulmonary antibacterial host defense. J Immunol. 177: 1833-7, 2006.

27) van Eck M, Berkhof H, Nicolson N, Sulon J. The effects of perceived stress, traits, mood states, and stressful daily events on salivary cortisol. Psychosom Med. 58: 447-58, 1996.

28) Vardar-Sengul S, Demirci $T$, Sen BH, Erkizan V, Kurulgan E, Baylas H. Human beta defensin-1 and -2 expression in the gingiva of patients with specific periodontal diseases. J Periodontal Res. 42: 429-37, 2007.

29) Ueda SY, Yoshikawa T, Katsura Y, Usui T, Fujimoto S. Comparable effects of moderate intensity exercise on changes in anorectic gut hormone levels and energy intake to high intensity exercise. $J$ Endocrinol. 203: 357-64, 2009.

30) Bishop NC, Walker GJ, Scanlon GA, Richards S, Rogers E. Salivary IgA responses to prolonged intensive exercise following caffeine ingestion. Med Sci Sports Exerc. 38: 513-9, 2006.

31) Akimoto T, Kumai Y, Akama T, Hayashi E, Murakami H, Soma R, Kuno S, Kono I. Effects of 12 months of exercise training on salivary secretory IgA levels in elderly subjects. Br J Sports Med. 37: 76-9, 2003.

32) Levine A, Zagoory-Sharon O, Feldman R, Lewis JG, Weller A. Measuring cortisol in human psychobiological studies. Physiol Behav. 90: 43-53, 2007.

33) Chrousos GP. Stressors, stress, and neuroendocrine integration of the adaptive response. The 1997 Hans Selye Memorial Lecture. Ann N Y Acad Sci. 851: 311-35, 1998.

34) Hill EE, Zack E, Battaglini C, Viru M, Viru A, Hackney AC. Exercise and circulating cortisol levels: The intensity threshold effect. $J$ Endocrinol Invest. 31: 587-591, 2008.

35) Minetto MA, Lanfranco F, Baldi M, Termine A, Kuipers H, Ghigo E. Corticotroph axis sensitivity after exercise: Comparison between elite athletes and sedentary subjects. J Endocrinol Invest. 30: 215-223, 2007.

36) Törnhage CJ. Salivary cortisol for assessment of hypothalamic-pituitary-adrenal axis function. Neuroimmunomodulation. 16(5): 284-9. Epub 2009 Jun 29. Review.

37) Urhausen A, Gabriel H, Kindermann W. Blood hormones as markers of training stress and overtraining. Sports Med. Oct; 20 (4): 251-76, 1995.

38) Mackinnon LT. Immunoglobulin, antibody, and exercise. Exerc Immunol Rev. 2: 1-35, 1996.

39) Bishop NC, Gleeson M. Acute and chronic effects of exercise on markers of mucosal immunity. Front Biosci. 14: 4444-56, 2009.

40) Steerenberg PA, van Asperen IA, van Nieuw Amerongen A, Biewenga A, Mol D, Medema GJ. Salivary levels of immunoglobulin A in triathletes. Eur J Oral Sci. 105: 305-9, 1997.

41) MacKinnon LT, Jenkins DG. Decreased salivary immunoglobulins after intense interval exercise before and after training. Med Sci Sports Exerc. 25(6): 678-83, 1993.

42) Starkie RL, Hargreaves M, Rolland J, Febbraio MA. Heat stress, cytokines, and the immune response to exercise. Brain, Behavior, and Immunity. 19: 404412, 2005.

43) Pedersen BK. Exercise and cytokines. Immunology and Cell Biology. 78: 532-535, 2000. 